This is an electronic reprint of the original article. This reprint may differ from the original in pagination and typographic detail.

\author{
Author(s): Kykyri, Virpi-Liisa; Karvonen, Anu; Wahlström, Jarl; Kaartinen, Jukka; Penttonen, \\ Markku; Seikkula, Jaakko
}

Title: $\quad$ Soft Prosody and Embodied Attunement in Therapeutic Interaction: A Multimethod Case Study of a Moment of Change

Year: $\quad 2017$

Version:

Please cite the original version:

Kykyri, V.-L., Karvonen, A., Wahlström, J., Kaartinen, J., Penttonen, M., \& Seikkula, J. (2017). Soft Prosody and Embodied Attunement in Therapeutic Interaction: A Multimethod Case Study of a Moment of Change. Journal of Constructivist Psychology, 30(3), 211-234. https://doi.org/10.1080/10720537.2016.1183538

All material supplied via JYX is protected by copyright and other intellectual property rights, and duplication or sale of all or part of any of the repository collections is not permitted, except that material may be duplicated by you for your research use or educational purposes in electronic or print form. You must obtain permission for any other use. Electronic or print copies may not be offered, whether for sale or otherwise to anyone who is not an authorised user. 
Soft Prosody and Embodied Attunement in Therapeutic Interaction: A Multi-method Case Study of a Moment of Change

Accepted for publication in the Journal of Constructivist Psychology (Editor's decision letter: 24-Apr-2016)

Authors:

Virpi-Liisa Kykyri, Ph.D.

Anu Karvonen, M.A.

Jarl Wahlström, Ph.D.

Jukka Kaartinen, Ph.D.

Markku Penttonen, Ph.D.

Jaakko Seikkula, Ph.D.

University of Jyvaskyla, Department of Psychology, Jyvaskyla, Finland

Author Note

Virpi-Liisa Kykyri, Department of Psychology, University of Jyvaskyla

Virpi-Liisa Kykyri, P.O. Box 35, FI-40014 University of Jyvaskyla, Finland.

virpi-liisa.kykyri@jyu.fi 
SOFT PROSODY AND EMBODIED ATTUNEMENT IN THERAPEUTIC INTERACTION

Soft Prosody and Embodied Attunement in Therapeutic Interaction: A Multi-method Case Study of a Moment of Change

In the social sciences and in psychotherapy research there has been increasing interest in the relational, affective, and embodied aspects of interactions (Cromby, 2012; Stern, 2004). Everyday experiences of affective attunement, which include achieving a connection with another person or sensing another person's feelings, are deeply embodied. It is highly likely that such experiences are clinically relevant, contributing to the construction of new personal meanings, which is a core element of therapeutic change. Thus, within constructivist psychotherapy, the manifestation of emotion is seen as pointing to an increase in the client's way of experiencing something; hence, a legitimate rule for a clinician is to "follow the affect trail" (Neimeyer, 2009). Nevertheless, there are problems in studying attunement, bearing in mind that during interactions people tend to adapt to others in ways that they are not even aware of. Affective attunement between two or more persons is assumed to happen intuitively, largely below conscious monitoring. Embodied experiences emerge and become sensed within a very short period of time, the "present moment" (Stern, 2004). They can exist as barely perceptible glimpses, but also as more striking experiences of intense emotionality, such as anger or sadness (Harré, 1986).

The concept of embodied attunement is rooted in developmental psychology. At the start of life, communication occurs mainly at the bodily level, consisting of concrete actions, such as vocal cues and mimicry, and also "perceptional qualities" or "vitality contours" such as timing, 
SOFT PROSODY AND EMBODIED ATTUNEMENT IN THERAPEUTIC INTERACTION

form, and intensity (Stern, 1985). These behavioral dimensions carry important relational information and are regulated in mutual interaction, within which the various attributes, including prosodic elements of speech, are turned into forms of feeling. Stern (1985) calls this process "affect attunement," and has proposed it as the basis of intersubjectivity in all human interaction. Experiences of embodied attunement consist of (i) a complex mixture of observable synchrony, i.e. similar verbal and nonverbal behaviors in the realm of micro-level social interaction, encompassing similar bodily responses that occur in a coordinated manner within a particular moment (Barrett, 2012), and (ii) non-observable elements such as bodily sensations, feelings and (vague) impressions or anticipations of how things are in a relationship, or how the ongoing interaction is developing (Shotter, 1993). The multi-layered nature of such experiences means that embodiment research calls for advanced designs and for approaches using mixed methods (Cromby, 2012).

The present study focused on the changes in prosody (i.e. the musical and embodied elements in speech) occurring in the course of one highly emotional episode within a psychotherapy dialogue between a client, a therapist, and a psychology student, who participated in this psychotherapy case as part of her studies. The aim of the study was to contribute to research on embodied attunement by presenting a case in which psychophysiological measures and interviews were utilized along with a qualitative analysis of social interaction. By this means we sought to determine how patterns of interaction - including what we have termed "soft prosody" - were related to the participants' bodily responses and to the interpretations they gave to the interaction in question. 
SOFT PROSODY AND EMBODIED ATTUNEMENT IN THERAPEUTIC INTERACTION

The present study is part of a research project called the Relational Mind in Events of Change in Multiactor Therapeutic Dialogues (Seikkula et al, 2015), which, to our knowledge, is the first to use a multi-actor psychotherapy interaction as a natural laboratory for studying the changes in bodily activity that occur during social interaction. The aim in the project is to focus on the comprehensive embodied flow of responsive events in dialogue between participants (Bakhtin, 1984; Seikkula, 2011). Drawing on intersubjectivity research (Stern, 2004; Trevarthen, 2001), the project aims to explore how emotions are communicated and negotiated, how empathy and compassion are performed, and how this may lead to affective regulation, exploration, and mutual change. The project seeks to integrate information on how clients and therapists synchronize their behavior with each other, not merely in dialogue, but also in their body movements and gestures, and in their autonomic nervous system (ANS) responses. While we acknowledge the importance of language and conversation as means by which people accomplish relational outcomes (Heritage, 1984; Strong et al., 2008), our focus is also, and equally, on participants' bodily responses, with the aim of discovering how bodily changes connect to processes of meaning-making in social interaction (Cromby and Nightingale, 1999; Lyons and Cromby, 2010). In addition, we are interested in the individual meanings and interpretations that participants give to interactions and experiences.

The ANS is a mediator of emotional reactions, and measures of the sympathetic activation, especially skin conductance (SC) and heart rate (HR), are well established correlates of emotional responses (Lang et al., 1998). Increased electrodermal activity, as measured by increased skin conductance responses (SCR) and the skin conductance level (SCL), has been 
SOFT PROSODY AND EMBODIED ATTUNEMENT IN THERAPEUTIC INTERACTION

reported to occur with most emotions (Kreibig, 2010). Since psychophysiological responses are integral elements of emotional experiences, and since they may derive from mental states that are not observable in overt behavior or in verbal reports, they can give useful information on the affective aspects of an interaction.

In the project in question, individual Stimulated Recall (SR) interviews (Kagan, Krathwohl, \& Miller, 1963,) also referred to as Interpersonal Process Recall (Elliott, 1986,) are conducted after the sessions. In these, clients and therapists are asked about their thoughts, feelings, impressions, and bodily sensations during the interaction under study. In the course of the interviews, video-taped extracts from the therapy session are used to facilitate the recall of the participants' subjective experiences. Although such experiences cannot be fully described in words, and although parts of the descriptions consist rather of reflections provoked by the extracts, individual interviews can provide important information, especially in relation to emotional moments of the interaction, since the emotions themselves often facilitate memorizing and recall (Sandi and Pinelo-Nava, 2007). In individual interviews, participants often share and comment on relevant issues, such as thoughts and feelings that they did not express during the actual interaction. Here it should be noted that there can be marked differences in participants' experiences of the same interaction, and in the interpretations given to them.

The present study originated from an observation of a moment of attunement within a psychotherapy session between one client, a therapist, and a student. In this episode, the client was weeping while she talked about painful experiences in her life. The impression of attunement was strong and consisted mainly of silences and gentle ways of talking. We became 
SOFT PROSODY AND EMBODIED ATTUNEMENT IN THERAPEUTIC INTERACTION

interested in this kind of interaction, encompassing what we here refer to as "soft prosody," i.e. the interlocutors' use of pauses, a lower volume, a slower rhythm, and a lower-pitched and more level intonation than in the surrounding speech. Later, a detailed analysis of the social interaction suggested that this episode also comprised a moment of therapeutic change in personal meanings. From inspection of the heart rate (HR) measurements conducted during the session, it emerged that for the client, this episode had, in physiological terms, been the most stressful moment of the entire session.

On the basis of these aspects, we concluded that the episode in question would offer rich material to study the multi-layered phenomenon of embodied attunement in psychotherapy interaction. We decided to focus on the use of soft prosody as an element of the observed attunement and of changes in meaning-making. In addition, we were interested in whether and how the signs of attunement in the interaction might be reflected in the participants' psychophysiological responses.

In everyday social interaction, information on the speaker's emotional state is conveyed through resources that include facial expressions, body movements and gestures, verbal expressions, and elements that combine the expression of emotion and action, such as laughter and crying (Peräkylä \& Sorjonen, 2012). Moreover, the prosodic features of speech, such as pitch, tempo, loudness, and pauses, affect the ways in which what is said is received by interlocutors. Such features are central elements which interlocutors modulate in conveying and receiving emotions in an interaction (Couper-Kuhlen \& Selting, 1996; Szczepek Reed, 2011). 
SOFT PROSODY AND EMBODIED ATTUNEMENT IN THERAPEUTIC INTERACTION

The present study focused on what we call "soft prosody." This is definable in terms of the following characteristics:

(i) the use of a low volume voice in the interaction. In everyday life, in conjunction with other prosodic phenomena, low-volume sounds are generally felt to be friendly and soothing;

(ii) the use of certain types of intonation, characterized by a low pitch and a reduced pitch range. In conjunction with low volume, these form an important element in a "softer" tone of voice, as referred to by Weiste and Peräkylä (2014);

(ii) the use of continuers, nods, and various facial expressions. The most common means of displaying affiliation, i.e. showing empathy and attempting to enter into a teller's unhappiness, include the use of continuers, e.g. "mm," "yeah" (Schegloff, 1982), nods (Stivers, 2008), and the showing of an affiliative (i.e. compassionate, caring) change in one's facial expression (Peräkylä \& Ruusuvuori, 2012).

(iii) Pauses are important ingredients of soft prosody. There is considerable variation in how silence is sensed, depending on the situation in which silence occurs. As noted by Johannesen $(1974,26)$, "silence takes on meaning only in a surrounding context of verbal and nonverbal symbols." Silence can be sensed as relaxing and comforting, and it can convey respect and compassion; however, it can also be sensed as uneasy or even frightening, or as an exercise of power. In psychotherapy, silence is often seen as a desirable element of the interaction, and one that can be a pathway to displays of affiliation and empathy (Hill, Thompson, \& Ladany, 2003). According to Levitt (2001), on the basis of clients' experiences of silences in individual psychotherapy, silences can be divided into neutral, productive, and obstructive types of silence. 
SOFT PROSODY AND EMBODIED ATTUNEMENT IN THERAPEUTIC INTERACTION

There is some evidence that there are more emotional, self-expressive, and reflective types of productive silences and fewer disengaged types of obstructive silences in the good-outcome psychotherapy dyads than in the poor-outcome dyads (Frankel et al., 2006).

The present study is related to a long tradition of studies on important moments in psychotherapy, which are often called as "significant moments" (Elliott, 1985; Elliott \& Shapiro, 1992). Research in the area has touched on clients' and therapists' perceptions of helpful or hindering moments, and on their possible productive role in the therapeutic processes (Timulak, $2007 ; 2010)$. There is some evidence that the relational and emotional aspects of an interaction may be crucial in significant moments of psychotherapy, and that clients may find these more important than the cognitive aspects of therapy that are more frequently highlighted by therapists (Timulak, 2010). On the basis of such findings, emotional aspects and attunement would appear to be relevant elements in significant moments of psychotherapy. Nevertheless, to our knowledge, research on significant moments has not paid much attention to the embodied aspects of interaction.

Even though empirical research on embodied attunement in clinical practice remains rare, some important observations have been made. Ramseyer and Tschacher (2011) found that synchronization of body movements may increase the experience of a good working alliance and contribute to a better outcome in therapeutic dyads. They observed that clients' experience of the session was related to this synchronicity. Observations of embodied attunement have also been conducted by focusing on the facial expression of emotions during psychotherapy interactions (Bänninger-Huber \& Widmer, 1999; Benecke, Peham, \& Bänninger-Huber, 2005; Darwiche et 
SOFT PROSODY AND EMBODIED ATTUNEMENT IN THERAPEUTIC INTERACTION

al., 2008). Marci, Ham, Moran, and Orr (2007) studied client and therapist dyads and found that client-perceived empathy was connected to good mutual concordance in skin conductance (SC) between the participants.

Dialogical practice and research have indicated that therapists synchronize their talk with the clients, for example by repeating the client's utterances and by integrating their own utterances with these. This in turn contributes to the therapeutic relationship and to the clients' experiences of it (Seikkula \& Arnkil, 2014). There is some evidence that clients tend to be more responsive to how things are being said in psychotherapy, rather than to the content of the therapist's utterances (Quillman, 2012). Lapides (2011) found that during emotionally tensed moments of a relational conflict, clients in couple therapy attend primarily to prosody, and also to body posture, gesture, and facial expressions. Geller and Porges (2014) have suggested that prosodic and other non-verbal elements of emotional interaction may have a central role in communicating safety and in creating a "therapeutic presence," i.e. the perception that a therapist is wholly engaged in and attuned with and for the client. Imel et al. (2014) found strong evidence for vocal synchrony in clinical dyads, as well as an association between synchrony and client empathy ratings. On the basis of these observations, they suggested that synchrony in physiological arousal could be mediated in part via vocal cues. Drawing on the work of Rice and Kerr (1986), Tomicic, Martinez, and Krause (2015) used a Vocal Quality Pattern (VQP) coding system to study the process of change in psychodynamic psychotherapy; they found that the process was embodied in the expressive vocal styles of the participants. 
SOFT PROSODY AND EMBODIED ATTUNEMENT IN THERAPEUTIC INTERACTION

Weiste and Peräkylä (2014) observed that therapists' formulations which led up to the validation of clients' emotions were characterized by prosodic continuity, meaning that they were produced with a similar prosody to that of the client's preceding turn. They found that the therapist also lowered her/his voice, spoke quietly, and used level intonation. The clients treated these formulations as validating, and as permission to feel what they felt. By contrast, formulations that led up to a challenge to the client's emotions were characterized by prosodic disjuncture: the therapist's prosody was different from the client's previous prosody, the pitch span in the therapist's turn was wider, and the therapist spoke with a voice that was higher and louder than the client's prior talk. The clients oriented themselves to these challenging formulations by viewing them as problematic; they might confirm them only partially, or reject them (Weiste \& Peräkylä, 2014).

Our first attempts (Seikkula et al, 2015) to study embodied attunement in couple therapy showed some clear psychophysiological responses, such as high stress, occurring in chronological coordination with important interactions in the session. We also discovered that attunement is often not a simple "all at the same time" phenomenon, but rather a complex phenomenon which changes over time. Thus, during a specific moment, one client can have a strong sympathetic synchrony with one therapist, but later in the session, the client can have more synchrony with another participant. The same design was used to study the significance of silent moments and soft prosody in one couple therapy session (Itävuori et al, 2015). From our analysis of the social interaction and of the participants' ANS responses, we noticed that even during moments with less overt vocalization, the participants were able to continue their 
SOFT PROSODY AND EMBODIED ATTUNEMENT IN THERAPEUTIC INTERACTION

conversation on fundamental issues, such as the permanence of the relationship and the possible separation of family members, both through their bodily responses and through soft prosody. These initial findings encouraged us to focus on specific episodes of the interaction; they indicated that soft prosody could have an important role in promoting embodied attunement within a psychotherapy interaction.

The design of the present study provided a rare opportunity to integrate information from several channels of interaction, namely (i) the therapeutic conversation within an important psychotherapy event, (ii) prosodic and other nonverbal elements of an interaction (regarded as more embodied elements of spoken language than the actual words), (iii) psychophysiological responses (as observed in parallel Autonomic Nervous System (ANS) measurements) during visible emotional expression (weeping), and (iv) participants' personal experiences (thoughts and feelings) from the episode, as they were reported in individual interviews conducted after the therapy session. We applied a multi-method approach with precise timing, aiming to explore (i) how soft prosody was used during one emotionally intense psychotherapy episode in which painful issues were processed, and (ii) whether and how this contributed to embodied attunement between the participants, and to therapeutic change. Our basic assumption was that soft prosody plays an important role in how the interlocutors experience mutuality and sharing within the relationship. On the basis of the intense emotionality during the episode, we expected to find responses in the participants' ANS as measured via SC and HR. We wished to discover whether there would be signs of synchrony in the participants' ANS, since these could indicate embodied attunement between the participants. Finally, we were interested to see how interactional patterns 
SOFT PROSODY AND EMBODIED ATTUNEMENT IN THERAPEUTIC INTERACTION

in the episode were related to patterns of bodily synchrony and to the participants' interpretations of the interaction.

\section{Method}

The Relational Mind research project is part of the research programme The Human Mind (Academy of Finland), and it is conducted at the University of Jyväskylä, Finland, in collaboration with five international partners. Within the project, data are gathered at the Psychotherapy Training and Research Center of the University of Jyväskylä. So far, the data consist of one individual psychotherapy case and twelve couple therapy cases. The Ethical Board of the University of Jyväskylä has approved the research, and all the participants have given their informed written consent.

\section{The Case and Design}

The data for this study were from a case with one female client and an experienced psychotherapist, and also a psychology student. When the client contacted the psychotherapy center she had self-defined her presenting problem as depression. She was an unemployed single parent. She indicated that she had serious problems in her relationships with her parents and friends. There were six sessions altogether, with the data for the present study coming from the third session. Progress in therapy was monitored by the Outcome Rating Scale (ORS), given to the client before each session, and by the Session Rating Scale (SRS) (Miller \& Duncan, 2004), 
SOFT PROSODY AND EMBODIED ATTUNEMENT IN THERAPEUTIC INTERACTION

given to the client and also to the therapist and the student after each session. In the third session, the SRS score for the client was 37.9 (with 36 illustrating an ideal working alliance) and the ORS score (indicating the amount of psychological distress) was 20.9 (the clinical cut-off being 25 or below). In the sixth session, the ORS score was 35.8, indicating a significant change for the better.

The participants were recorded using two cameras. These showed the entire setting on a split screen (therapist/student/client). In addition, a precise facial image of every participant was recorded using three additional cameras. During the third therapy session, the therapist, the student, and the client all wore the following ANS measuring equipment: (i) As a measure of electro-dermal activity (EDA), skin conductance (SC) was registered with two electrodes attached to the non-dominant palm. (ii) Respiration was measured with a fabric belt fastened around the lower chest. (iii) There was continuous heart rate monitoring, starting a day before the therapy session, continuing during the therapy session, and ending after the SR interview. The SR interviews were recorded with two cameras: one recorded the facial expressions of the interviewee (client, or therapist, or student) while the other included the whole setting. During these latter interviews, finger pulse volume and bodily movements were also recorded. The heart rate was recorded with Firstbeat Bodyguard equipment, using two disposable electrodes attached to the chest. Other ANS activities were collected via BrainProducts sensors and data acquisition systems.

The SR interviews were conducted three to four hours after the third therapy session. During the interviews, a researcher met all three participants, one at a time, to show them four video 
SOFT PROSODY AND EMBODIED ATTUNEMENT IN THERAPEUTIC INTERACTION

extracts encompassing two- to four-minute episodes from the therapy session. The researcher interviewed the participants concerning the thoughts and feelings they had experienced during these episodes. All the participants watched the same extracts, which the researcher had selected on the basis of: (i) visible emotional expression, (ii) notable changes in social interaction (such as dialogue after several monologues), (iii) changes in skin conductance (i.e. a strong response from one participant, or changes that indicated the synchronization of two or more participants), or (iv) a combination of these. The individual interviews lasted about 35-40 minutes per participant. The participants were encouraged to share their thoughts at any time while watching the extracts.

One conversational episode within the third therapy session was selected for detailed analysis in the present study. This 91-second episode occurred in the middle of the session (from $19 \mathrm{~min} .29$ secs. to $21 \mathrm{~min}$.). This episode was selected for further analysis on the following grounds:

(i) The episode consisted of the following elements: expressing and receiving emotions, conveying empathy, offering formulations, and showing awareness and insight. With all these elements in place, the episode was considered to represent an important psychotherapeutic moment.

(ii) It was rich in incidences of soft prosody, i.e. the interlocutors' use of pauses, a lower volume, a slower rhythm, and lower-pitched and more level intonation than in the surrounding speech. 
SOFT PROSODY AND EMBODIED ATTUNEMENT IN THERAPEUTIC INTERACTION

(iii) It involved strong visible emotions, and was therefore of interest from a psychophysiological perspective.

(iv) The HR variables indicated that the episode contained the client's highest physiological stress of the entire session.

(v) Individual interviews concerning the participants' experiences of the episode were available.

\section{Analysis}

The video-recorded therapy session and the interviews were transcribed verbatim, using detailed notations to indicate interactional features (see Appendix 1). The original Finnish-language recordings and transcriptions were used in the various stages of the analysis. The extracts selected for this article were translated into English after the overall analysis. The Finnish transcripts are available on request from the first author.

The first author conducted the detailed analysis of the social interaction in the selected episode, focusing on both the contents of the speech and the prosodic and other non-verbal elements of the interaction. Thereafter, the third author watched the extracts and commented on the analysis, which was then further elaborated on the basis of his observations. The analysis was informed by ideas from conversational analysis (Goffman, 1979; Sacks, Schegloff, \& Jefferson, 1974; Silverman \& Peräkylä, 1990), and discursive psychology (Edwards \& Potter, 1992; Potter, 2003). Particular use was made of methods for analyzing prosody (Couper-Kuhlen \&Selting, 1996; Barth-Weingarten et al., 2010) and emotions (Peräkylä \& Sorjonen, 2012) within 
SOFT PROSODY AND EMBODIED ATTUNEMENT IN THERAPEUTIC INTERACTION

interactions. In addition, the concept of footing (Goffman, 1979) was used. This refers to the ways in which shifts in the alignment of the speaker and the listener are used as a resource, for example in situations when one participant starts to speak on behalf of another, taking on the other's voice or perspective.

The second author conducted a separate analysis of the HR data to define stressful moments from the session as a whole. The Firstbeat Bodyguard (Firstbeat Technologies) recording device makes it possible to obtain second-by-second calculations of stress and relaxation, thus reflecting the activity of the sympathetic (absolute stress vector, ASV) and parasympathetic (absolute relaxation vector, ARV) nervous system (e.g. Kinnunen et al., 2006). The ASV is calculated from respiratory variables derived from the HR, high frequency power (HFP), low frequency power (LFP), and HRV-derived respiratory variables. The algorithm is based on the principle that the ASV is high when the HR is elevated, HRV is reduced, and the respiration rate is low relative to the HR and HRV.

To detect possible signs of bodily synchrony during the selected episode, correlations were calculated between the participants' skin conductance responses (SCR). SC recordings were down-sampled to a 1s sampling interval, slopes for successive values were calculated, and each value was replaced with a 5s moving average in order to remove small amounts of amplitude noise from the signal. Pearson correlations were then calculated between the participating pairs (client to therapist, client to student, therapist to student). SC raw data were used to determine whether the participant's arousal level (based on the SC) was increasing or decreasing. 
The transcribed SR interview responses of the therapist, the student, and the client were then thematically analyzed by the first author. Within the analysis, all comments in which a participant clearly referred to the selected episode were included, whether they occurred after seeing this particular episode or at another moment during the SR interview. The participants' individual interviews were used to complete, modify, or confirm the findings.

Finally, the findings of the separate analyses were integrated to produce a multi-layered description of the interaction in the episode.

\section{Results}

In this Results section we first present a transcription and analysis of the social interaction in the selected episode. Thereafter we present the corresponding ANS data, and finally observations from the SR interviews.

In the extract, the client is marked as $\mathrm{C}$, the therapist as $\mathrm{T}$, and the psychology student as $\mathrm{S}$. Since the client's highest ASV peak during the entire session occurred during the selected episode, it is marked in the transcript as, for example, ((client's ASV starts to rise)), and commented on along with the analysis of the social interaction.

\section{The Interactional Episode}


In this session, the client talked about her disappointment at not finding any job despite her new degree, and her struggle to get good grades in it. She started to talk about painful and abusive experiences in her relationships with friends and relatives. She felt that she had been used by others for different purposes, and that this experience had lasted a long time. The client specifically named her father, sister, and a close friend, who had frequently asked her to do various tasks for them, but who had shown no willingness to help the client in return. Particularly during her studies, the client had felt that she would have needed help and support, but had not received any. In talking about these experiences, the client started to express her unhappiness by weeping and looking sad.

\section{Extract 1:}

1. C: it feels bad now when I notice what is going on

2. T: $\quad{ }^{\circ} \mathrm{yes}^{\circ}$

3. C: $\quad \mathrm{mm}(($ nods, wiping tears from her cheek))

4. T: @earlier you did not notice it (1) and well (.) the exploitation just then

5. $\quad(($ gentle voice, gestures with hand $))($.$) continued@$

6. C: $\quad$.hh yes $().(($ wiping tears $))$ continued ((nods))

7. $\mathrm{T}: \mathrm{mm}$

8. C: $\quad$ so that I must just be le- kind of mo- (.) to a smaller extent in contact ((with 9. $\quad$ them)) so that I (.) kind of myself (.)

10. T: $\quad \mathrm{mm}$

11. C: $\quad$ feel OK((nodding)) (1) 
In extract 1, the client's emotionality enters the interaction, and she wipes tears from her cheek (lines 3,6). The therapist uses soft prosody (lines 4-5) and continuers (lines 7 and 10) in displaying emotional affiliation with the weeping client.

Earlier in the conversation, the client had mentioned that at first she had not noticed how she was being exploited by her family and friends. In line 1 she indicates that becoming aware of how she was used makes her feel bad. The therapist's formulation in lines 4-5 repeats the client's earlier utterances and focuses on the notion that this relationship pattern has continued. The client confirms this in line 6. The therapist responds to this with the continuer "mm" (line 7). The client seems to treat this as an invitation to say more. The client says that from now on, she must avoid those who made use of her earlier (lines 8-9 and 11).

\section{Extract 2:}

12. T: $\quad$.hhh $(($ gestures with hand $)) \downarrow$ but $\underline{\text { is }}$ it so that now that you $\uparrow$ see it that you have 13. C: ((wiping tears))

14. T: been used in those relationships then ((looks at T2)) from that comes ((looks at

15. C)) (.) @that bad feeling of having been undervalued ((nods)) and ${ }^{\circ}$ not

16. $\quad \operatorname{respected}^{\circ} @(($ gentle voice $))(1)$ which was $\uparrow$ not $(($ gestures away from the client $))$

17. there earlier (.)@or was it ((the bad feeling)) there even then $\varrho^{\circ}(($ gentle voice $))$ ((client's ASV starts to rise)) 
SOFT PROSODY AND EMBODIED ATTUNEMENT IN THERAPEUTIC INTERACTION

The therapist pays no attention to the client's idea of being less in contact with her relatives (see lines 8-9), and instead offers another formulation (starting from line 12) which focuses on the previous topic, i.e. the client's bad feelings. Lexically, this repeats and summarizes the client's earlier utterances, but at the same time, it forms a significant conversational choice, in that it highlights and emphasizes some of the client's utterances, but passes over some other parts of her speech. This choice seems to work as a delicate and indirect suggestion for the client to live through this emotion (bad feeling), rather than as creating ways of avoiding it. The therapist's formulation is offered as a question. There is a rising intonation on the words "see" (line 12) and "not earlier" (lines 16-17), which focus the therapist's question on the client's claim that she had not noticed the pain earlier. The client continues to weep, and wipes tears from her cheek (line 13). As can be seen in line 15, the therapist uses soft prosody when referring to the client's experiences of being "undervalued" and "not respected." Soft prosody is used again in line 17, when the therapist articulates, almost in a whisper, "or was it ((the bad feeling)) there even then." The therapist's question very gently challenges the client's idea of having been ignorant of her bad feelings earlier. Here the use of soft prosody seems to downgrade, not to upgrade, the therapist's idea. It appears that by doing this, the therapist is displaying sensitivity to the delicate nature of this conversational domain, and conveying affiliation with the weeping client. At the same time, he empathetically challenges the client's idea by inviting the client to engage in emotional experiencing, and by refocusing the client's emotion. As marked in line 17, the client's stress vector starts to increase during the therapist's second formulation, and this increase continues during the following extract (Extract 3). 


\section{Extract 3:}

18. C: $\quad$ ((wiping tears)) well that was a time of try- then I was trying

19. T: $\quad(($ coughs $))$ yeah

20. C: I was trying that (.) to be the ((turning her head from side to side)) the right kind

21. ((of person) $)$ [or something like that

22. T: $[(($ nods $))$

23. T: $\quad$ yeah

24.

25. C: now I think this ((wiping tears)) sorrow has to come out (.)

26. T: $\quad \uparrow \mathrm{mh}(($ nodding $))$

27. C: $\quad$ so that somehow I $\uparrow$ must see (.)

28. T: $\quad \mathrm{mm}$

29. C: this pain means the same as seeing

30. T: $\quad \mathrm{mm}$

31. C: $\quad$ or does it ((laughs))

The client's turn (in lines 18-21) indicates that she notices the challenging content in the therapist's second formulation (shown in extract 2). She treats the therapist's turn as a question and appears to see herself as having to account for not having been aware of the exploitation: "it was a time of trying." She has tried to solve this situation by "trying to be the right kind ((of person))." There is a three-second pause (line 24) after the therapist's nod (line 22) and "yeah" 
SOFT PROSODY AND EMBODIED ATTUNEMENT IN THERAPEUTIC INTERACTION

(line 23), which can be seen as a means of displaying emotional affiliation with the weeping client.

Wiping tears from her cheek, the client says that now it is time for sorrow (line 25). Thus, what the client has earlier called a bad feeling is now renamed as sorrow. The therapist displays emotional affiliation by nodding and using the continuer "mm" (line 26). This minimal response is expressed with high intonation, and the client treats it as an invitation to say more by responding that she "must see" it now, possibly referring to the abusive pattern in her relationships (line 27). After another "mm" on the part of the therapist, the client continues by sharing her (somewhat vague) idea that feeling "pain" would mean the same to her as "seeing" (line 29). What was previously called a bad feeling and recently renamed as sorrow is now renamed by the client as pain. The therapist again responds with a continuer. The client laughingly asks (line 31) "or is it," thus seeking the therapist's confirmation of her idea. The therapist responds to this with a gentle voice and a smile (Extract 4, line 32).

\section{Extract 4:}

32. T: @well ((with a gentle voice, smiling and looking at the client))

33. C: $\quad \mathrm{mm}$

34. T: $\quad$.hh so you have@(.) very (.) $\uparrow \operatorname{co}(\mathrm{h})$ nciously like

35. chosen it $[().(($ client's highest ASV peak, starts to decrease $))$

36. C: $\quad$ [yea:h

37. T: $\quad$ that (.) well this (.) can't ((looks at S, gestures with his hand)) go on

38. any more ((looks at the client)) and (.) now I'm ((points to the client with his 
39. hand)) doing differently and (.) ${ }^{\circ}$ then it feels painful ${ }^{\circ}$ ((with a gentle voice))

40. C: $\quad \mathrm{mm}($.$) but this is how it must be ((wiping tears)) (.) because$

41. $\uparrow$ there is no return to the past ((laughs))

The therapist again uses soft prosody when offering his third formulation (starting from line 32). It differs from the others by being not a question but a statement. A soft and gentle, even a whispering voice is used both in preparing ("well," line 32) and ending ("othen it feels painful'," lines 37-38) his formulation, which not only cites the client's earlier words, but also highlights the client's active role in choosing her ways to deal with the situation. This is done mainly by lexical choices and by changes in footing. First of all, the therapist uses the pronoun "you" (line 34) when referring to the choice that the client has "consciously" made. Secondly, he changes the footing, while repeating the client's talk, by using the pronoun I in "now I'm doing differently" (line 38), even though it is obvious that the therapist is not referring to himself but to the client. This is confirmed in the therapist's gesture, which points to the client. This carefully designed formulation positions the client as an active agent who considers what is best for herself, even if it means experiencing pain. The client confirms this (lines 40-41) by saying laughingly that "there is no return to the past." Thus, there is an overall movement in these 41 lines, from "a bad feeling" (line 1) to "sorrow" (line 25) to "pain" (line 29), with the client recategorizing this in terms of being finally able to "see" (line 29) that this is "how it must be" (line 40). The client's stress vector reaches the highest peak of the entire session in line 35 and then starts to decrease very rapidly. 


\section{Extract 5:}

42. T: $\quad \mathrm{mm}$

43. S: $\quad \mathrm{mm}$

44. C: $\quad$ ((wiping tears, sniffs)) $\mathrm{mm}$

45.

46. T: $\quad \mathrm{mm}(.) \mathrm{mm}(($ nodding $))$

47. C: $\quad$ ((clicks her tongue)) I must become ((points to herself))

48. $\quad{ }^{\circ}$ stronger ${ }^{\circ}(($ with a gentle voice $))$ inside (.) not just superficially

49. (7)

50. T: $\quad$ ((nodding)) stronger inside

51. C: $\quad$ yeah (.) throughout this pain

52. T: $\quad$ yes ((looks at the client gently with a smile))

53. C: $\quad \mathrm{nn}$

54. T: $\quad(($ nodding $))$

55.

After the client's turn, the therapist, the student, and the client give minimal responses " $m m$," the client wipes tears from her cheek, and there is a four second pause. In line 46, the therapist nods and gives another minimal response. In line 48, the client says that she needs to become "stronger inside." Interestingly, the client pronounces the word "stronger" in a very warm and gentle tone and with lower volume than in the surrounding talk. It seems that the client has adopted the therapist's way of talking when she addresses speech to herself, thus displaying 
SOFT PROSODY AND EMBODIED ATTUNEMENT IN THERAPEUTIC INTERACTION

to herself the same compassion that the therapist conveyed to her a moment before. There is a seven-second pause in line 49, which is followed by the therapist's nod and repetition of the client's words "stronger inside" in line 50. The therapist's turn invites the client to continue, which she does by saying "throughout this pain" in line 51. The therapist responds with a gentle smile and "yes," the client says " $n n$," and the therapist nods (in lines 52-54). The episode ends with a three-second pause.

\section{Absolute Stress Vector (ASV)}

The client's highest ASV peak (see Figure 1 and extracts 1-3) occurred at time $20 \mathrm{~min} .30 \mathrm{sec}$. from the start of the session. In the course of the conversation, the client had openly expressed her sadness by weeping and by talking about her experience of pain. The client's stress vector started to rise just after the therapist's second formulation (line 19); it reached its highest peak during the therapist's third formulation (line 35), and after that, started to decrease very rapidly. The client's ASV indicated that physiologically, this conversational moment was stressful for her. Interestingly, the therapist's fourth highest ASV peak occurred close to the client's highest peak.

\section{[Insert figure 1 about here]}

Figure 1. Absolute stress vectors calculated from the entire therapy session. The client's highest ASV peak and the therapist's fourth highest peak occurred within the analyzed episode and are marked in the figure. The student's ASV reaches zero at certain times (discontinuity in 
SOFT PROSODY AND EMBODIED ATTUNEMENT IN THERAPEUTIC INTERACTION

the line), indicating that the student is in a relaxed or "other state" (neither stressed nor relaxed) according to the algorithm.

\section{Skin Conductance during the Selected Episode}

As shown in Figure 2, the SC correlations from the episode were either negative or near zero from about 20 seconds into the episode, and during the client's highest stress peak. This was the point when the therapist was offering formulations, and when the client was processing thoughts and feelings about her relationships. Towards the end of the episode (after 60 seconds), when there were long silences and indications of attunement and harmony in the social interaction, all the correlations became positive. This happened between the therapist and the student (correlation 0.56), then between the client and the student (0.69), and finally between the client and the therapist (0.83). The SC data (Figure 3) showed that all the participants' SCs decreased towards the end of the episode, indicating less arousal/ sympathetic activation in the participants. During the therapist's formulations, the client and the therapist showed almost mirroring curves in their SC recordings, indicating that when the client's arousal increased, the therapist's decreased, and vice versa.

[insert Figure 2 about here]

Figure 2: SC correlations between the participants in the selected episode, divided into Extracts 1-5. The black line shows the correlation between the client and the therapist, the grey line the correlation between the client and the student, and the dashed line the correlation 
SOFT PROSODY AND EMBODIED ATTUNEMENT IN THERAPEUTIC INTERACTION

between the therapist and the student. Vertical lines delineate the extract periods (Extracts 1 to 5). Note positive correlations in all dyads after 60 seconds.

[insert Figure 3 about here]

Figure 3: SC data for each participant, Extracts 1-5. The vertical range is auto-scaled for each participant. Vertical lines delineate the extract periods. Note opposite trends in client's and therapist's SC in Extracts 3 and 4.

\section{Stimulated Recall Interview Responses}

In the Stimulated Recall Interview (SRI), the client started to weep once again after watching the episode. She said that she could not remember much about this episode, except the fact that she was weeping. It was only after seeing the video that she was able to recall why she was weeping. The client had felt safe during the therapy session: the therapist and the student were trustworthy and they had helped her in bringing to the fore important issues, and in dealing with them. The client noted her word choice, "trying to be the right kind ((of person))" (Extract 3, lines 20-21) and commented: "no matter how good and decent I will ever be, it will not be enough for them" (her family and friends). The client had realized this during the therapy session, and this insight was really important to her.

The therapist recalled being surprised and puzzled by the intensity of the client's emotionality during the episode. In the session, the client had been very skillful in articulating her feelings, but these descriptions had been on a general level. This made it necessary for 
SOFT PROSODY AND EMBODIED ATTUNEMENT IN THERAPEUTIC INTERACTION

therapist to invite more concrete descriptions. At the same time, he sensed a need to be careful in the interaction, and this prevented him from proceeding too quickly or deeply into painful topics. The therapist had experienced it as confusing that the client was talking about "big issues, like her whole life story in two sentences." He said that this might have been behind his wariness in searching for therapeutic ways to proceed. He commented on the client's words, "stronger inside" (Extract 5, lines 46-47), and recalled having thought: "these words sound trivial but, within this particular interaction, they seem to carry a special meaning, which is not easy to follow." He had been concerned about this thought during that particular moment.

The student had been concerned about how she could stay calm while the client was so sad. There were moments when she noticed that she was starting to feel something that resembled the client's emotions. The student was also worried about the client, who seemed to be becoming more and more distressed. The student recalled that towards the end of this episode, her worries started to decrease. When the client said that she must face and process her pain, this was a relief; it reassured the student that the client felt that she would survive, despite her current sadness and pain. Student mentioned the client's laughter (Extract 3, line 31 and Extract 4, line 40) and said that this might have served the function of relieving the emotionally loaded atmosphere in the session.

\section{Summary of the findings}


SOFT PROSODY AND EMBODIED ATTUNEMENT IN THERAPEUTIC INTERACTION

Table 1 offers an integrated overview of the findings from different modalities during the five conversational extracts; also the participants' individual reports of their experiences of these.

[Insert Table 1 about here]

Table 1: Summary of the findings

\section{Discussion}

This study aimed at exploring how "soft" prosody was used in discussing painful issues during one emotionally intense episode in a single psychotherapy case. During this episode the client actively worked on her painful experiences, by talking about them and by expressing emotions related to them. Given the evidence underlining the importance of empathic communication in psychotherapy (e.g. Elliott, Bohart, Watson, and Greenberg, 2011) and the role of non-verbal aspects (Imel et al., 2014; Weiste and Peräkylä, 2014), we anticipated that soft prosody would be a prominent feature of expressions of affiliation. It appeared that soft prosody did indeed have a role in how the therapist and student showed affiliation with the weeping client. According to our interpretation, this had important consequences for the therapeutic interaction, in that it increased the sense of safety, and facilitated the ability of the client to handle painful experiences, and to get involved in personal meaning-making. The high SRS score from the session illustrated an ideal alliance, and in her SR interview, the client confirmed that the therapist and student had created safety within the interaction, and that this had helped her to talk about important issues. 
SOFT PROSODY AND EMBODIED ATTUNEMENT IN THERAPEUTIC INTERACTION

In the episode studied, the client started to use soft prosody herself, adopting some of the therapist's gentle ways of talking while she was talking to herself.

During the interaction, the therapist offered several formulations which encouraged the client to live through her emotions and to give new meanings to her experiences. In these, soft prosody was used in an interesting manner, particularly in the therapist's second formulation. This was a challenging formulation, and one that was offered in an exceptional way. Especially towards the end of the therapist's turn, it was offered very gently, in a soft voice, and at a low volume. This finding was somewhat surprising, since it differed from the observations of Weiste and Peräkylä (2014). In their studies, challenging formulations were usually produced with prosodic disjuncture, i.e. with a higher volume and pitch. As we interpret it, offering this challenging formulation with soft prosody helped the client to continue to work through and express her feelings at a stressful and emotional moment. This led to a change in the meanings that the client attached to her emotions: the analysis of the social interaction indicated that something that was initially called "feeling bad" was first changed to "sorrow" and then into "pain." In fact (in the words of the client), "this is how it must be" if the client is to "see" how she has been taken advantage of - something she had not noticed before. The client used the therapist's emotional re-interpretation as an element in this change. In the SR interview, the client referred to her insight concerning the impossibility of her efforts to please her significant others. This was an insight that she had arrived at during the event, and she said that this understanding was important to her. Thus, a notable change in meaning-making took place, one that was observable in the episode and later confirmed by the client in her interview. In the later 
SOFT PROSODY AND EMBODIED ATTUNEMENT IN THERAPEUTIC INTERACTION

sessions, the client indicated that she had gained more resources to defend herself against exploitation in her relationships. In addition, a notable change in her well-being was visible in her ORS scores in the sixth session.

From an embodiment perspective, one interesting finding concerned how the active therapeutic work during the episode was reflected in the participants' bodies. The period of about 40 seconds, during which the change in the client's meaning-making occurred, also included the most physiologically stressful seconds of the entire session for the client. The client's ASV started to increase after the therapist's second formulation, and her highest stress peak occurred during the therapist's third formulation - i.e. the formulation to which the client responded with a change in the meaning she attached to her experiences. This resonates with findings of Levitt et al. (2004), to the effect that painful experiences and distress can initiate transformational insight. One of the therapist's highest ASV peaks also occurred close to the client's highest stress peak, during his third formulation. This stress peak may have been a reaction to how the client was responding to this formulation.

There is another important finding related to the client's stress. The fact that the client's highest ASV peak occurred during the episode signified both the emotional importance of the moment and the psychological effort that she was putting into processing it. As mentioned earlier, the therapist's formulations might have contributed to the increase in the client's physiological stress, by encouraging the client to "live through" her emotions (and thus intensifying the emotional load), and by inviting the client to self-reflect. At these points the formulations were cognitively demanding. In her SR interview, the client gave an important 
SOFT PROSODY AND EMBODIED ATTUNEMENT IN THERAPEUTIC INTERACTION

description of her psychological experience of the interaction, when she said that it was only after seeing this episode on the video that she was able to remember why she was weeping in the session. Here it is worth noting that moments of therapeutic processing and insight could involve processes similar to those evidenced in learning. On the basis of the "inverted U-shape effect" found in investigations of stress and learning (e.g. Sandi \& Pinelo-Nava, 2007), it has been suggested that there may be an optimal level of stress in learning settings. It is possible that during the episode we studied, the client's stress was more than would have been optimal to memorize the focus and content of this particular conversation, despite the fact that the client was able to process painful issues in a way that was meaningful for her. It is also possible that the intense emotionality prevented the consolidation of this particular memory. Although emotions often boost learning and memory, a loss of explicit memory can also occur in situations that have an intense emotional charge (Squire \& Zola, 1998).

From an embodiment research perspective, an interesting finding concerns how, within only 91 seconds, two entirely different patterns of synchrony emerged between the participants. The first pattern showed a kind of "complementary synchrony," i.e. a mirroring tendency in the arousal of the client and the therapist, occurring during the active therapeutic processing. The second pattern showed what could be called "matching synchrony," i.e. a simultaneous decreasing tendency in the arousal of all the participants during a silent moment of the interaction. Initially, when the therapist's first formulation was offered, there was no bodily synchrony between the skin conductances of any of the participants. However, in the middle of 
SOFT PROSODY AND EMBODIED ATTUNEMENT IN THERAPEUTIC INTERACTION

extract 2, on the evidence of the almost mirroring patterns in the SC recordings, it would seem that the client's arousal increased as the therapist's arousal decreased, and vice versa.

As we interpret it, this kind of complementary synchrony pattern was related to the differing roles and tasks of the client and the therapist in this particular interaction. The therapist's questions and formulations, and the client's responses to these, formed an interactional pattern which was reflected in their bodily responses. For the client, the therapist's formulations created a challenge to "stay within the trouble" of experiencing, expressing, and processing her emotions. For the therapist, the challenge was how to regulate this pressure so that the client would not become overwhelmed. This was confirmed later in the SR interview, in which the therapist talked about his difficulties in understanding the client's open emotionality. Related to this, he had articulated two therapeutic tasks: to proceed very carefully, and to challenge what the client was expressing by inviting more concrete descriptions. For the student, the interactional challenge seemed to be how to handle the emotional load in the interaction, as she also reported in her SR interview.

Towards the end of the episode the arousal levels of the participants started to decrease, as measured through changes in SC. The client's physiological stress was also considerably reduced. This happened within a phase of the interaction consisting mainly of long silences, soft prosody, and non-verbal interaction. It was this moment of observed attunement that attracted our attention when we first observed it, during the data gathering stage. During this late phase of the interaction, indications of bodily synchrony between the participants could be observed, as seen in the good positive correlation in all the participants' SC recordings. This happened first 
SOFT PROSODY AND EMBODIED ATTUNEMENT IN THERAPEUTIC INTERACTION

between the therapist and the student, then between the client and the student, and finally, between the client and the therapist. In her SR interview the student confirmed that towards the end of the episode she started to think that the client would come through the crisis; hence the student herself felt more relaxed. In his SR interview, the therapist said that he had pondered the client's aim of becoming "stronger inside." The comment had initially struck him as fairly trivial, but he became aware that it was important for the client. It is possible that the therapist's thought processes here could be related to the synchrony that latterly emerged between himself and the client.

The results of this study suggest that soft prosody was an important conversational tool in this particular psychotherapy case and that it contributed both to the emotional attunement between the participants and to the therapeutic change that was observed. It is, however, important to keep in mind that the use of these delicate discursive tools might have been less conscious than a detailed reading of the interaction would suggest. It is likely that changes of this kind happen automatically in an interaction, without conscious monitoring or choice. Moreover, it is important to bear in mind that what happened during this short episode was situated and case-specific. Even though detailed descriptions of the therapeutic interaction can have some transferability to other clinical settings, the results of the present study should be seen as tentative. For reliable conclusions, one would need more cases and more developed ways of analyzing this kind of multi-layered data.

Despite these caveats, the study does have a contribution to make, in that it provided a detailed description of how an empathetic therapist's re-formulation(s) worked within a 
SOFT PROSODY AND EMBODIED ATTUNEMENT IN THERAPEUTIC INTERACTION

therapeutic interaction. To our knowledge, such observations have not previously been made in relation to three levels of therapeutic interaction, involving (i) how soft prosody was used to gently encourage the client to process and rename her experiences, leading to an observed therapeutic change in the social interaction, (ii) how this change was observable at the bodily level in terms of changes in the participants' arousal, and (iii) how it was confirmed via the client's experience of the interaction. In clinical practice, there is a wide consensus on the importance of facilitating both emotion-processing and meaning-making in clients. The present case study provided an example of the intertwined and embodied nature of these processes. We suggest that during the observed "matching synchrony," the dialogue between the participants occurred more on the bodily level than in language, leading to a shared experience of affective attunement, and contributing to a change in meaning-making. Soft prosody and silences are easily audible "cues"; they can facilitate the noticing of events when "sensing" rather than talking is a central activity in the interaction. Our overall message for clinicians is to pay attention to these aspects, and to develop one's own preparedness to be open to and resonate with the client in preverbal interaction.

The finding of two different kinds of synchrony is in itself important. It suggests that when studying attunement and synchrony, it is not enough to focus on the matching synchrony alone. There is a need to look also at mirroring patterns, which can form a kind of complementary synchrony, and to investigate how these are related in social interaction. In the present study, these complementary patterns in the participants' arousal seemed to be related to the broader interactional directions observable in the session. Our results open up new possibilities for 
SOFT PROSODY AND EMBODIED ATTUNEMENT IN THERAPEUTIC INTERACTION

studying embodiment during significant events within psychotherapy, through combining multilayered data and mixed methods approaches. For instance, studies on how the 'therapist's presence" (Geller and Porges, 2014) is carried out and experienced in an interaction, and also studies on ruptures in therapeutic interaction, could benefit from these approaches. The physiological stress of clients during therapeutic processing also seems to be an important issue, and one which would be worthy of further study. 
SOFT PROSODY AND EMBODIED ATTUNEMENT IN THERAPEUTIC INTERACTION

\section{References}

Bakhtin, M. (1984). Problems of Dostojevskij's poetics: Theory and history of literature, Vol. 8. Manchester, UK: Manchester University Press.

Barrett, L.F. (2012). Emotions are real. Emotion, 12(3), 413- 429.

Barth-Weingarten, D., Reber, E., Seltin, M. (Eds.) (2010). Prosody in interaction. Amsterdam: Benjamins.

Benecke, C., Peham, D., \& Bänninger-Huber, E. (2005). Nonverbal relationship regulation in Psychotherapy. Psychotherapy Research, 15(1-2), 81-90.

doi:10.1080/10503300512331327065.

Bänninger-Huber, E. \& Widmer, C. (1999). Affective relationship patterns and psychotherapeutic change, Psychotherapy Research, 9, 74-87.

Couper-Kuhlen, E. \& Selting, M. (Eds.) (1996). Prosody in Conversation: Interactional studies. Cambridge: Cambridge University Press.

Cromby, J. (2012). Feeling the way: Qualitative clinical research and the affective turn. Qualitative Research in Psychology, 9, 88-98.

Cromby, J. \& Nightingale, D.J. (1999). What's wrong with social constructionism? In D.J. Nightingale \& J.Cromby (Eds.), Social Constructionist Psychology. A Critical Analysis of Theory and Practice (pp. 1-19). Buckingham: Open University Press.

Darwiche, J., de Roten, Y., Stern, D., von Roten, F.C., Corboz-Warnery, A \& FivazDepeursinge, E. (2008). Mutual smiling episodes and therapeutic alliance in a therapistcouple discussion task. Swiss Journal of Psychology, 67 (4), 231-239.

Edwards, D., \& Potter, J. (1992). Discursive psychology. London: Sage. 
SOFT PROSODY AND EMBODIED ATTUNEMENT IN THERAPEUTIC INTERACTION

Elliott, R. (1985). Helpful and nonhelpful events in brief counseling interviews: An empirical taxonomy. Journal of Counseling Psychology, 32, 307-322.

Elliott, R. (1986). Interpersonal process recall (IPR) as a process research method. In L. S. Greenberg \& W. M. Pinsof (Eds.), The psychotherapeutic process: A research handbook (pp. 503-528). New York: Guilford.

Elliott, R., Bohart, A. C., Watson, J. C., \& Greenberg, L. S. (2011). Empathy. Psychotherapy, 48(1), 43-49. DOI:10.1037/a0022187.

Elliott, R., \& Shapiro, D. A. (1992). Clients and therapists as analysts of significant events. In S. G. Toukmanian \& D. L. Rennie (Eds.), Psychotherapy process research: Theory-guided and phenomenological research strategies (pp. 163-186). Beverly Hills, CA: Sage.

Frankel, Z. , Levitt, H.M., Murray, D.M., Greenberg, L.S. \& Angus, L. (2006). Assessing silent processes in psychotherapy: an empirically derived categorization system and sampling strategy, Psychotherapy Research, 16:5, 627-638.

Geller, S.M. \& Porges, S.W. (2014) Therapeutic Presence: Neurophysiological Mechanisms Mediating Feeling Safe in Therapeutic Relationships. Journal of Psychotherapy Integration, 24(3), $178-192$.

Goffman, E. (1979). Footing. Semiotica, 25, 1-29.

Harré, R. (Ed.). (1986). The Social Construction of Emotion. Oxford: Blackwells.

Heritage, J. (1984). Garfinkel and ethnomethodology. Cambridge: Polity Press.

Hill, C.E., Thompson, B.J., \& Ladany, N. (2003). Therapist use of silence in therapy: A survey. Journal of Clinical Psychology, 59(4), 513-524.

Imel, Z.E., Barco, J.S., Brown, H., Baucom, B.R., Baer, J.S., Kircher, J., \& Atkins, D.C. (2014). 
SOFT PROSODY AND EMBODIED ATTUNEMENT IN THERAPEUTIC INTERACTION

Synchrony in vocally encoded arousal as an indicator of therapist empathy in motivational interviewing. Journal of Counseling Psychology, 61(1), 146-53.

Itävuori, S., Korvela, E., Karvonen, A., Penttonen, M., Kaartinen, J., Kykyri, V.L., \& Seikkula, J. (2015). The significance of silent moments in creating words for the not-yet-spoken experiences in threat of divorce. Psychology, 6, 1360-1372. doi:10.4236/psych.2015.611133.

Johannesen, R.L. (1974). The functions of silence: A plea for communication research. Western Speech, 38(1), 25-35.

Kagan, N., Krathwohl, D.R. \& Miller, R. (1963). Stimulated Recall in therapy using video tape A case study. Journal of Counseling Psychology, 10(3), 237-243.

Kinnunen, M-L., Rusko, H., Feldt, T., Kinnunen, U., Juuti, T., Myllymäki, T. et al.( 2006). Stress and relaxation based on heart rate variability: Associations with self-reported mental strain and differences between waking hours and sleep. http://www.firstbeat.fi/.

Kreibig, S. (2010). Autonomic nervous system activity in emotion: A review. Biological Psychology, 84, 394-421.

Lang, P.J., Bradley, M.M., Cuthbert, B.N. (1998). Emotion, motivation and anxiety: Brain mechanisms and psychophysiology. Biological Psychiatry, 44,1248-1263.

Lapides, F. (2011). The implicit realm in couples therapy: Improving right hemisphere affect-regulating capabilities. Clinical Social Work Journal, 39, 161 - 169. DOI 10.1007/s10615-010-0278-1.

Levitt, H. M. (2001). The sounds of silence in psychotherapy: Clients' experiences of pausing. Psychotherapy Research, 11, 295-309. 
SOFT PROSODY AND EMBODIED ATTUNEMENT IN THERAPEUTIC INTERACTION

Levitt, H.M., Frankel, Z., Hiestand, K., Ware, K., Bretz, K., Kelly, R., McGhee, S., Nordtvedt, R.T., \& Raina, K. (2004). The transformational experience of insight: A life-changing event. Journal of Constructivist Psychology, 17, 1-26.

Marci, C.D., Ham, J., Moran, E. \& Orr, S.P. (2007). Physiological correlates of perceived therapist empathy and social-emotional process during psychotherapy. The Journal of Nervous and Mental Disease, 195(2), 103-111.

Miller, S. D., \& Duncan, B. L. (2004). The outcome and session rating scales: Administration and scoring manual. Fort Lauderdale, FL: Author.

Neimeyer, R. (2009) Constructivist Psychotherapy. Distinctive Features. London and New York: Routledge.

Peräkylä, A. \& Ruusuvuori, J. (2012). Facial expression and interactional regulation of emotion. In A.Peräkylä \& M.-L. Sorjonen (Eds.). Emotion in interaction. (Pp. 64-91). New York: Oxford University Press. DOI: 10.1093/acprof:oso/9780199730735.003.0004.

Peräkylä, A. \& Sorjonen, M.-L. (2012). (Eds.) Emotion in interaction. New York: Oxford University Press.

Potter, J. (2003). 'Discursive Psychology: Between Method and Paradigm', Discourse \& Society, 14(6), 783-794.

Quillman, T. (2012). Neuroscience and therapist self-disclosure: Deepening right brain to right brain communication between therapist and patient. Clinical Social Work Journal, 40, 1 9. DOI: $10.1007 / \mathrm{s} 10615-011-0315-8$.

Ramseyer, F. \& Tschacher, W. (2011). Nonverbal synchrony in psychotherapy: Coordinated 
SOFT PROSODY AND EMBODIED ATTUNEMENT IN THERAPEUTIC INTERACTION

body movement reflects relationship quality and outcome. Journal of Consulting and Clinical Psychology, 79(3), 284-295. DOI: 10.1037/a0023419.

Rice, L.N. \& Kerr, G.P. (1986). Measures of client and therapist vocal quality. In Greenberg, L.S., \& Pinsof, W.M. (Eds). The psychotherapeutic process: A research handbook. Guilford clinical psychology and psychotherapy series, (pp. 73-105). New York, NY, US: Guilford Press.

Sacks, H.,Schegloff, E., \& Jefferson, G. (1974). A simplest systematics for the organization of turn-taking in conversation. Language, 50, 696-735.

Sandi, C. \& Pinelo-Nava, T. (2007). Stress and Memory: Behavioral Effects and Neurobiological Mechanisms. Neural Plasticity, DOI: 10.1155/2007/78970.

Schegloff, E.A. (1982). Discourse as an interactional achievement: Some uses of 'uh-huh' and other things that come between the sentences. In D. Tannen (Ed.), Analyzing discourse: Georgetown University Roundtable on Languages and Linguistics 1981 (pp. 71-93), Washington DC: Georgetown University Press.

Seikkula, J. (2011) Becoming Dialogical: Psychotherapy or a Way of Life? The Australian and New Zealand Journal of Family therapy, 32, 179-193

Seikkula, J. \& Arnkil, T.E. (2014). Open dialogues and anticipations: Respecting otherness in the present moment. Helsinki: THL.

Seikkula, J., Karvonen, A., Kykyri, V-L, Kaartinen J., \& Penttonen, M. (2015). The Embodied Attunement of Therapists and a Couple within Dialogical Psychotherapy: An Introduction to the Relational Mind Research Project, Family Process, doi: 10.1111/famp.12152. 
SOFT PROSODY AND EMBODIED ATTUNEMENT IN THERAPEUTIC INTERACTION

42

Shotter, J. (1993). Conversational Realities: constructing life through language. London: Sage Publications.

Silverman, D., \& Peräkylä, A. (1990). AIDS counseling: The interactional organization of talk about "delicate" issues. Sociology of Health \& Illness, 12(3), 293-318.

Squire, L. R. \& Zola, S. M. (1998). Episodic memory, semantic memory, and amnesia. Hippocampus, 8, 205-211.

Stern, D.N. (1985). The Interpersonal World of the Infant. New York: Basic Books.

Stern, D. (2004). The present moment in psychotherapy and everyday life. New York: Norton.

Stivers, T. (2008). Stance, alignment, and affiliation during storytelling: When nodding is a token of affiliation. Research on Language and Social Interaction, 41(1), 31-57.

Strong, T., Busch, R., \& Couture, S. (2008). Conversational evidence in therapeutic dialogue. Journal of Marital and Family Therapy, 34 (3), 388-405.

Szczepek Reed, B. (2011). Analyzing conversation. An introduction to prosody. Basingstoke: Palgrave Macmillan.

Timulak, L. (2007). Identifying core categories of client identified impact of helpful events in psychotherapy - a qualitative meta-analysis. Psychotherapy Research, 17, 305-314.

Timulak, L. (2010). Significant events in psychotherapy: An update of research findings. Psychology and Psychotherapy: Theory, Research and Practice, 83, 421-447.

Tomicic, A., Martinez, C., \& Krause, M. (2015). The sound of change: A study of the psychotherapeutic process embodied in vocal expression. Laura Rice's ideas revisited, Psychotherapy Research, 25:2, 263-276, DOI: 10.1080/10503307.2014.892647.

Trevarthen, C. (2001). Intrinsic motives for companionship in understanding: Their origin, 
SOFT PROSODY AND EMBODIED ATTUNEMENT IN THERAPEUTIC INTERACTION

development, and significance for infant mental health. Infant Mental Health Journal, 23, 95-131.

Weiste, E. \& Peräkylä, A. (2014). Prosody and empathic communication in psychotherapy interaction. Psychotherapy Research, DOI: 10.1080/10503307.2013.879619. 


\title{
Appendix 1: Transcript notation
}

\author{
Symbol \\ yes (1) me too \\ yes (.) me too \\ ((wiping tears)) \\ I think- I think so \\ official \\ $\underline{\text { underlining }}$ \\ [and well on the whole \\ ${ }^{\circ}$ and it feels bad ${ }^{\circ}$ \\ @you get that bad feeling@ \\ th)a(h)ke

\section{Meaning} \\ Figures in rounded brackets represent inter- and mid- \\ turn silences, hand-timed in seconds. \\ The period in rounded brackets represents "micro-pauses" of less \\ than 0.2 seconds. \\ Double rounded brackets contain relevant contextual \\ and non-verbal information added by the transcribers. \\ A single dash following a word or letter(s) indicates an \\ abrupt cut-off in the flow of speech (stammering). \\ Upward-pointing arrows indicate rising intonation. \\ Underlining indicates emphasis. \\ Overlapping utterances are marked by single square brackets. \\ A degree sign indicates significantly lower volume than in the \\ surrounding speech. \\ The @ symbol locates a change in the speaker's voice (for \\ example indicating where a more gentle tone of voice begins and \\ ends). \\ Added h's within rounded brackets indicate laughter within the \\ speech.
}




\section{SOFT PROSODY AND EMBODIED ATTUNEMENT IN THERAPEUTIC INTERACTION}

Table 1. Summary of findings $(\mathrm{C}=$ client, $\mathrm{T}=$ therapist, $\mathrm{S}=$ student $)$

\begin{tabular}{|c|c|c|c|c|c|}
\hline Extract & Conversation & Prosody & $\begin{array}{l}\text { Skin conductance } \\
\text { (SC) } \\
\text { synchrony }\end{array}$ & $\begin{array}{l}\text { Absolute } \\
\text { Stress } \\
\text { Vector(ASV) }\end{array}$ & $\begin{array}{l}\text { Personal experiences recalled } \\
\text { in Stimulated Recall Interview } \\
\text { (SRI) }\end{array}$ \\
\hline 1 & $\begin{array}{l}- \text { C's emotional } \\
\text { expression } \\
\text { (weeping) } \\
\text { - T showing } \\
\text { affiliation } \\
\text { - T's first } \\
\text { formulation }\end{array}$ & $\begin{array}{l}\text { - T uses soft } \\
\text { prosody in } \\
\text { showing } \\
\text { affiliation and } \\
\text { in } \\
\text { formulation }\end{array}$ & • No synchrony & & $\begin{array}{l}\text { - C starts to weep in her SRI. } \\
\text { - C did not remember why she } \\
\text { was crying in the session until } \\
\text { she watched the video clip. } \\
\text { - T had been surprised at the } \\
\text { intensity of C's emotion, and } \\
\text { made a conscious choice to } \\
\text { invite more concrete answers. } \\
\text { - S had experienced emotional } \\
\text { contagion }\end{array}$ \\
\hline 2 & $\begin{array}{l}\text { - C's emotionality } \\
\text { continues. } \\
\text { T's second } \\
\text { formulation }\end{array}$ & $\begin{array}{l}\text { - T uses soft } \\
\text { prosody in } \\
\text { formulation }\end{array}$ & $\begin{array}{l}\text { - Complementary } \\
\text { synchrony } \\
\text { between C \& T }\end{array}$ & $\begin{array}{l}-C^{\prime} \text { s ASV } \\
\text { starts to } \\
\text { increase }\end{array}$ & $\begin{array}{l}\text { - S worried about C becoming } \\
\text { "more and more distressed" } \\
\text { - T felt there was a need to } \\
\text { proceed carefully and not to } \\
\text { enter too deeply into painful } \\
\text { topics. }\end{array}$ \\
\hline 3 & $\begin{array}{l}\text { - C's comment: } \\
\text { "trying to be the } \\
\text { right kind of } \\
\text { person" } \\
\text { - Change in C's } \\
\text { meaning-making: } \\
\text { "bad feeling" into } \\
\text { "sorrow" and into } \\
\text { "pain" }\end{array}$ & $\begin{array}{l}\text { - Soft } \\
\text { prosody not } \\
\text { used } \\
\text { - 3-second } \\
\text { pause } \\
\text { between } \\
\text { turns }\end{array}$ & $\begin{array}{l}\text { - Complementary } \\
\text { synchrony } \\
\text { between C \& T }\end{array}$ & $\begin{array}{l}-C^{\prime} \text { s ASV } \\
\text { increase } \\
\text { continues }\end{array}$ & $\begin{array}{l}- \text { C points to her comment } \\
\text { about trying to please her } \\
\text { significant others, which she } \\
\text { sees as "mission impossible." } \\
\text { She had had this insight in the } \\
\text { session, and said that it was } \\
\text { really important for her. }\end{array}$ \\
\hline 4 & $\begin{array}{l}\text { - Therapist's third } \\
\text { formulation } \\
\text { constructs client } \\
\text { as an active agent } \\
\text { - Change in C's } \\
\text { meaning-making: } \\
\text { "pain" which "has } \\
\text { to be," articulated } \\
\text { with laughter }\end{array}$ & $\begin{array}{l}\text { - T uses soft } \\
\text { prosody } \\
\text { extensively in } \\
\text { his } \\
\text { formulation. }\end{array}$ & $\begin{array}{l}\text { - Complementary } \\
\text { synchrony } \\
\text { between C \& T }\end{array}$ & $\begin{array}{l}-C^{\prime} \text { 's highest } \\
\text { ASV peak for } \\
\text { the whole } \\
\text { session; ASV } \\
\text { then starts to } \\
\text { decrease } \\
\text { rapidly } \\
\text { - T's } 4^{\text {th }} \\
\text { highest ASV } \\
\text { peak of the } \\
\text { session }\end{array}$ & $\begin{array}{l}\text { - S mentions C's laughter and } \\
\text { shares an observation that it } \\
\text { might have been her way of } \\
\text { relieving the emotionally } \\
\text { tensioned moment. }\end{array}$ \\
\hline 5 & $\begin{array}{l}\text { - C articulates an } \\
\text { aim to "become } \\
\text { stronger inside (-) } \\
\text { throughout this } \\
\text { pain." }\end{array}$ & $\begin{array}{l}- \text { C uses soft } \\
\text { prosody in } \\
\text { her turn } \\
\text { - Long } \\
\text { silences }\end{array}$ & $\begin{array}{l}\text { - Synchrony, firstly } \\
T \text { \& S, secondly C } \\
\text { \& S, thirdly C \& T }\end{array}$ & $\begin{array}{l}\text { - C's ASV } \\
\text { decrease } \\
\text { stopped. }\end{array}$ & $\begin{array}{l}\text { - T was puzzled about C's } \\
\text { comment "stronger inside," } \\
\text { which he felt was superficial, } \\
\text { but still important for C. } \\
\text { - S felt relieved at C's thought }\end{array}$ \\
\hline
\end{tabular}




\begin{tabular}{|l|l|l|l|l|l|}
\hline $\begin{array}{l}\bullet \text { T and S affiliative } \\
\text { - Minimal } \\
\text { responses "mm", } \\
\text { nods, gentle } \\
\text { smiles }\end{array}$ & $\begin{array}{l}\text { between the } \\
\text { turns }\end{array}$ & & & & that she would survive. \\
\hline
\end{tabular}

Figures

Figure 1:

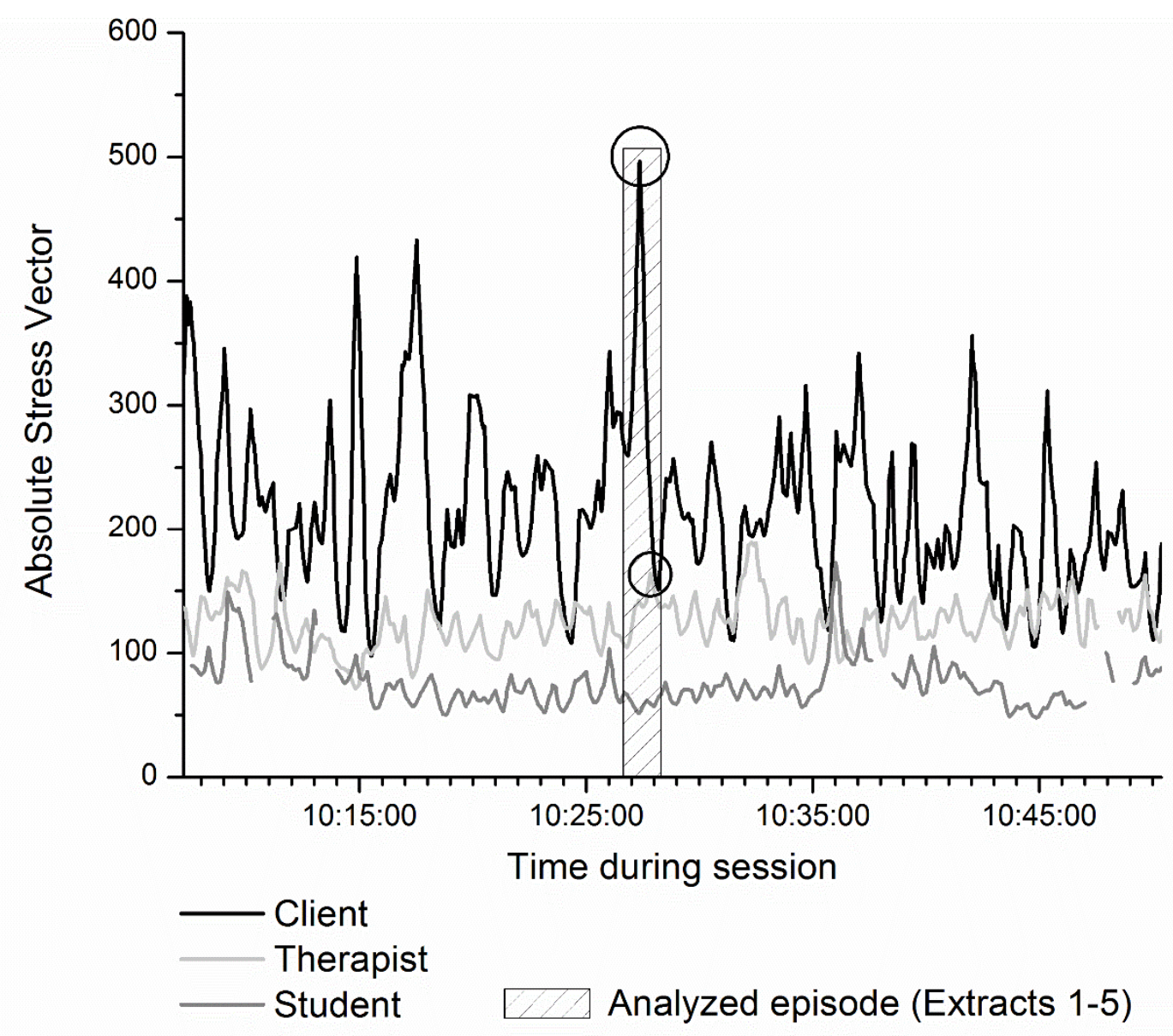


SOFT PROSODY AND EMBODIED ATTUNEMENT IN THERAPEUTIC INTERACTION

47

Figure 2: 


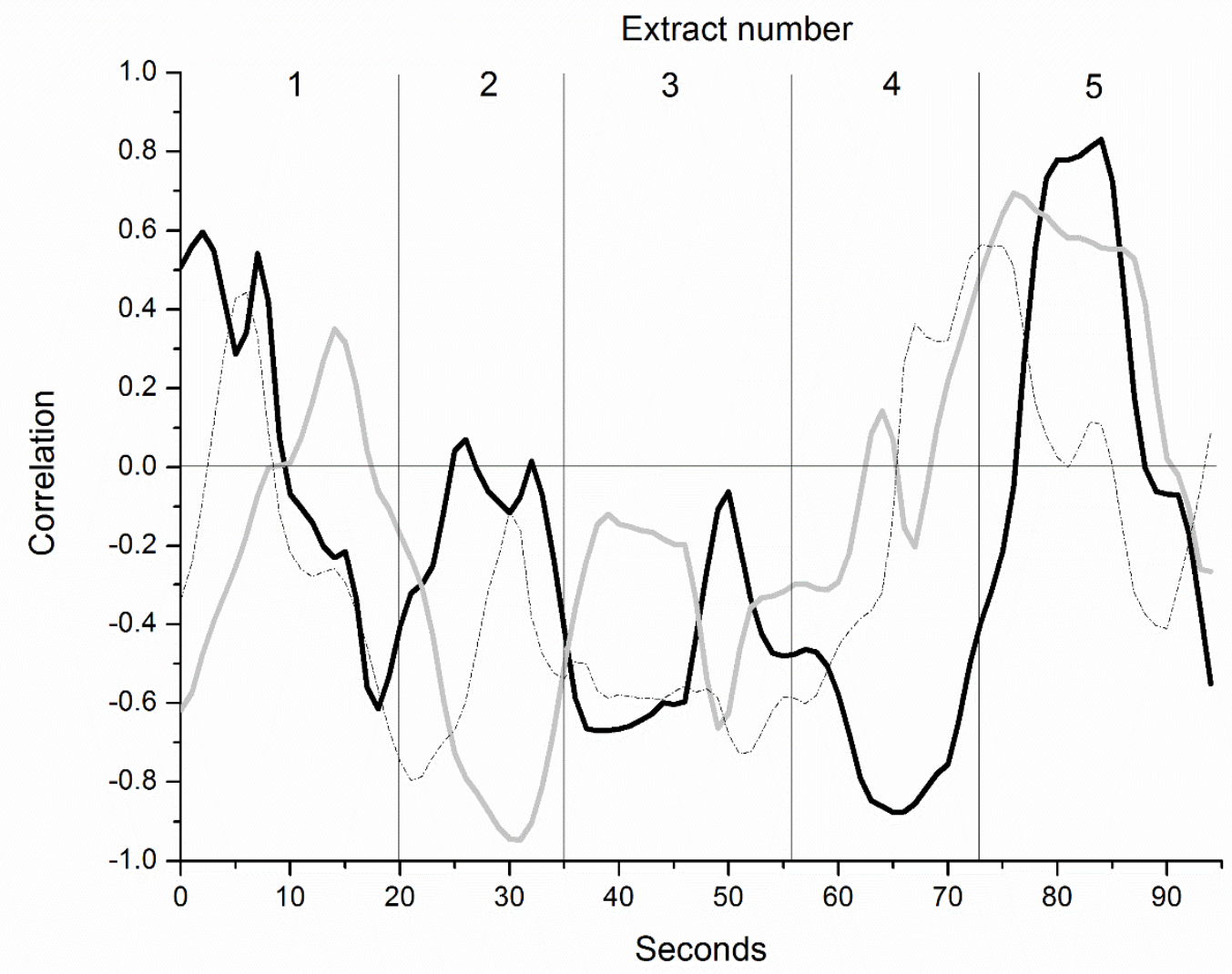

Client and Therapist

Client and Student

Therapist and Student 
Figure 3:

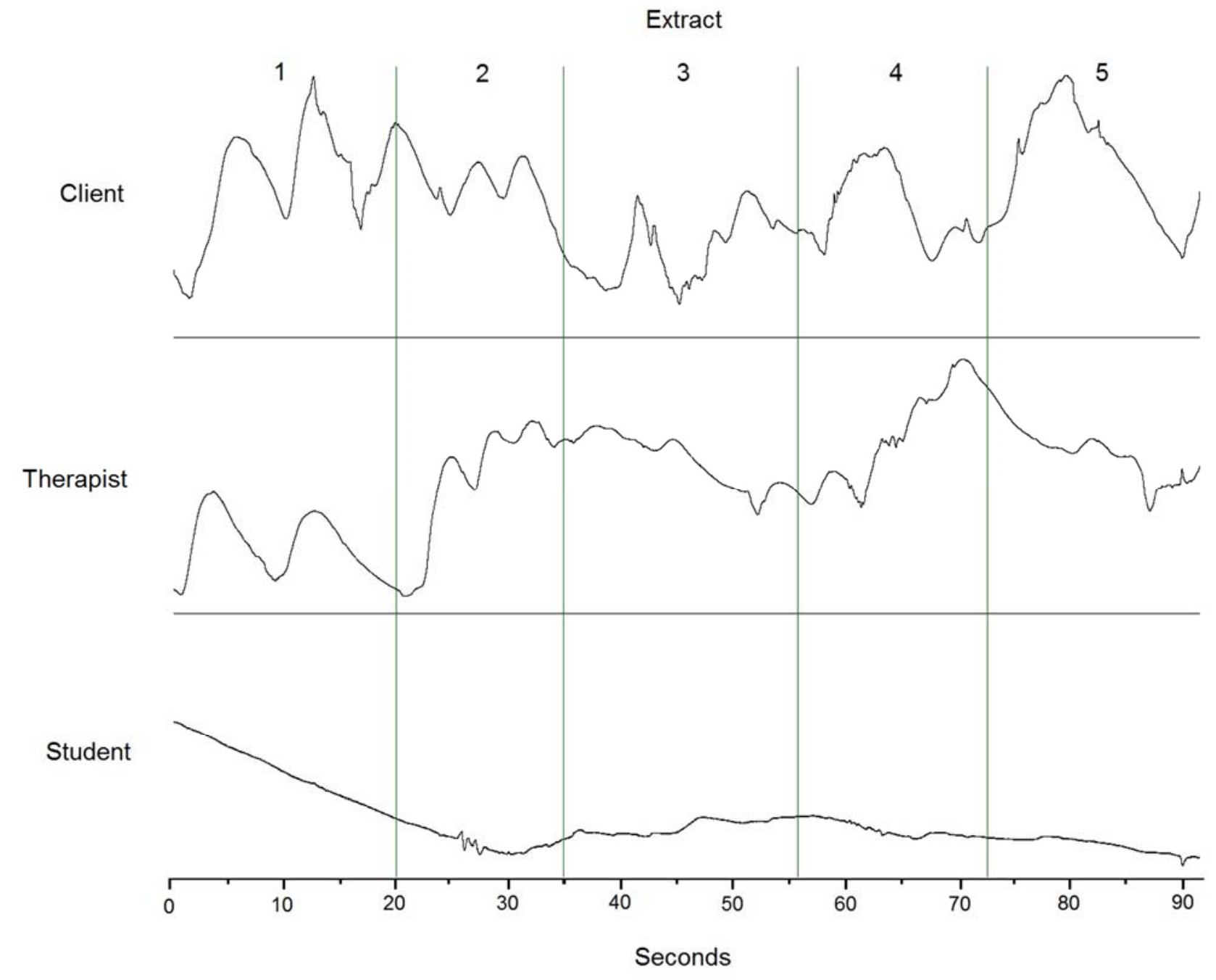

